\title{
A HISTORY OF INFANT FEEDING \\ PART III: EIGHTEENTH AND NINETEENTH CENTURY WRITERS
}

BY

\author{
IAN G. WICKES
}

(RECEIVED fOR PUblication July 2, 1953)

\section{Eighteenth Century Writers}

The social conditions in the eighteenth century have been described at some length in Part II because it is impossible to study the progress of infant feeding without examining the background which has so profoundly influenced its every aspect. We shall now proceed to consider in more detail the individual contributions to the subject which were made by the more important physicians who lived and worked in this momentous epoch.

M. Ettmüller (1644-83) strictly belongs to the seventeenth century but his 'Practice of Physic' (p. 677), which he wrote when he was professor at Leipzig, was first translated into English in 1699, and the second edition, from which the following excerpts are taken, was published in 1703 under the title of 'Ettmüller Abridged'. The diseases of men and women are fully dealt with in the earlier part and the diseases of children occupy Book V.

This work, though scarcely original in most respects, contains the first definite instruction to put the baby to the breast during the colostrum period, a practice which folk-lore usually forbids. Ettmüller also believed that it was unnecessary to give honey or castor oil to rid the newborn infant of the highly poisonous meconium which 'taints the Nourishment with a preternatural Acidity', for the 'beestings' were purgative. He believed also that breast milk could not be assessed so much by its thickness or taste, but rather by a variation in its more subtle qualities as exemplarized by the transmission of the nurse's character and temperament. The usual caution against overfeeding is found on page 621 : 'Nothing is more apt to disorder the child than suckling it too often, since large quantities of Milk stagnating in the Stomach, must needs corrupt and occasion Crudities, especially if fresh Milk be pour'd in before the preceeding be digested.' On the next page he traces a curious sequence starting with the evil effects of venery on the milk of the nurse which causes it to curdle in the infant's stomach setting up in him an antipathy for cheese in later life - a train of events which heralds the case histories of modern psychiatrists!

Finally Ettmüller comments upon the practice of pre-chewing the food by the nurses (p. 623):

'Tis customary among Nurses to attenuate the Child's food in their Mouths before they give it, and indeed 'tis true that a healthy Nurse's Spittle is of use for promoting a quick digestion: But if scorbutic Salts be lodged in her gums, or if a Cacophymy prevail in her Body, it is too apt a Vehicle for conveying a morbifical Tincture into the Child's Body."

William Cadogan's (1711-97) 'Essay upon the Nursing and Management of Children from their Birth to 3 Years of Age was written for, and subsequently published by, the General Committee of

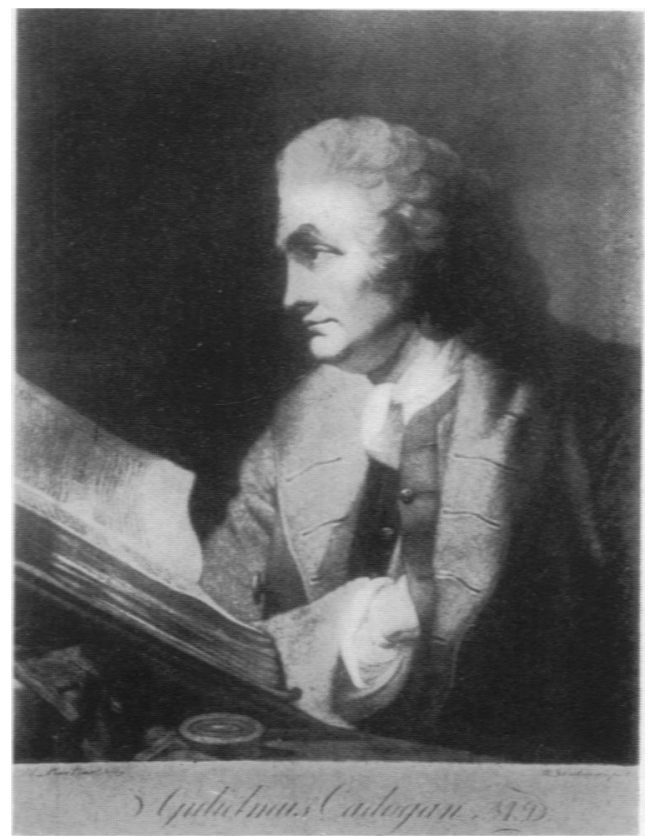

Fig. 6.-William Cadogan, a pioneer in infant feeding. Reproduced from 'History of Paediatrics' by Still by kind permission of the Oxford University Press. 
the Foundling Hospital in 1748, and its thirty odd pages are delightful and thrilling to read since they are so full of common sense and so free from 'hypothetical reasonings' which, he says, so frequently misled physicians in the past. Cadogan was scathing, too, about the midwives of his day for on page 4 he wrote :. . there is great reason to fear that those Nurses, who yet retain many of these traditional Prejudices (the use of herbs, roots and drugs etc.) are capitally mistaken in the Management of Children . . . and often do much harm where they intend to do good, by fancying Nature has left a great deal to their Skill and Contrivance'. A criticism which is still unhappily applicable in some measure to doctors and nurses today.

Cadogan was primarily concerned with the feeding and clothing of children, whom he said were in general overcloathed and overfed, and fed and cloathed improperly". It was still the common practice, as originally advocated by Soranus, to salt the newborn and then to bind the head and limbs very tightly to prevent the development of deformities, and at the same time to restrict almost all movement. It was largely due to Cadogan's influence that swaddling was finally discarded. He also preached against another custom of his day, namely, as soon as the child was born, to cram a Dab of Butter and Sugar down its throat, a little Oil, Panada, Caudle, or some such unwholesome Mess so that they set out wrong and the Child stands a fair chance of being made sick from the First Hour. It is the custom of some to give a little roast Pig to an Infant which it seems is to cure it of all the Mother's longings' (p. 14).

If mother's milk was unobtainable, a wet nurse was the next best thing and she should be middle aged (i.e. between 20 and 30 , a sad commentary on the expectation of life in the eighteenth century), but Cadogan believed that the current practice of sending the infant to be suckled 'out of doors' was less humane than exposure in the Roman fashion. Hand feeding, however, was equally dangerous since only one in three survived it and the skill of a good Physician would be necessary to manage it rightly". Cow's milk should not be boiled because this alters the taste, destroys the sweetness and makes it 'heavier", and artificial food generally was not simple enough:

- Their paps, panadas, gruel etc. are generally enriched with Sugar, Spice and sometimes a Drop of Wine; neither of which they ought ever to taste', but he allowed beer at the end of the first year. -They should not be laid on their Backs to be fed, but held in a sitting posture, that swallowing may be easier to them, and that they may more readily discover when they have had enough. When they have come to be about Six months old, and their
Appetite and Digestion grows strong, they may be fed three times a Day; which I think they ought never to exceed their whole Lives after.'

Before concluding his brilliant essay Cadogan recommended early weight bearing to develop the limbs and plain speaking to the child rather than the use of the 'Mamby Pamby Stile'.

In submitting his work to the Governors of the Hospital, he asked them to regard it as a foundling 'to do with it what you will', and he concluded with this apt testimony to his own method: 'I am a Father, and have already practised it with the most desirable Success.

N. Brouzet's essay on the 'Medicinal Education of Children and the Treatment of their Diseases. was published in Paris in 1754, and in London in the following year. It is well worth a close study for on page XIV of the Preface he shows at once that, like Cadogan, he has largely freed himself from the shackles of tradition:

-We have scarcely a single precept on the diet of children well established by a discussion of the advantages and inconveniences of the received practice. All that has been written on the choice of nurses and the nourishment of children is hardly anything more than a collection of prejudices.

He dealt harshly with the sentiments of many previous authors and described Walter Harris's treatise as 'very short, and executed with little care'. Of normal breast feeding he wrote (p. 110):

-All nurses, and even those of Princes, that are under the direction of Physicians, give the breast to the infant as often as he seems to desire it, and wait until he leaves it himself. Thus the quantity is varied according to the appetite of the infants, and I believe there can be no danger in suffering them to satisfy their hunger."

Indeed Brouzet is the first writer to take pity on the hungry baby who has been so sadly neglected in comparison with the overfed infant. His quotation from Joubert (Erreurs Populaires Tome I, p. 548) on page 61 bears repetition:

$\because$. our women are afraid of being slaves to their children: ... but some of them are such slaves to their pleasures, that they won't suffer the wench to bring them the squalling brat to receive the breast if it is not his hour, but had rather that she would walk about with him, sing him some fine songs, or rock him till he goes to sleep... the infant whose belly is empty, and tormented with hunger before his usual hour, cannot sleep, and to appease or falsify him with a song is mere mockery. I would fain know whether the nurse, having a good appetite, would, instead of her supper, be contented with a song ... We have a proverb which says "the hungry belly has no ears" and another "the empty belly is not easily contented with words". But I am in company says the lady, and would you have them bring my child, for me to shew my breast?' 
Brouzet thought that ideally two, or at most three feeds daily would be the best method of promoting a healthy digestion, but he was sufficiently practical to appreciate that, whether one liked it or not, hungry babies must be fed more often.

He particularly displayed his originality with regard to breast milk for, so far as I am aware, he is the only historical writer on the subject, apart from van Helmont whom he quoted, to dare to suggest that it may not be the most suitable food for infants regardless of whether it comes from the mother or a wet nurse. Should we not try to improve upon nature and provide an aliment which is free from the defects of breast milk? He proceeded to discuss the problem by asking three questions (p. 76):

(1) Should infants be nourished with milk? Universal approval satisfied him that they should, but van Helmont had advised feeding with panada made of bread slightly boiled with small beer, sweetened with clarified honey and finally diluted with beer to make it fluid, a mixture which would not become sour or corrupt, and which was free from the diseases and vices transmitted by milk. Brouzet pleaded for large scale experimentation to test the efficacy of van Helmont's formula for, as he wisely commented, 'reasoning alone can never be the foundation of medicinal precepts'.

(2) Should infants be nourished with woman's milk? 'All the people in the north feed their infants with cow's milk and it is universally allowed that these people are stronger and less subject to diseases than the southern nations.' He concluded that there was no evidence against cow's milk and weaning difficulties at nine months are obviated by its use.

(3) Should it be the milk of their own mothers? In spite of the sentiments of moralists, male midwives, politicians, writers and many physicians, Brouzet pointed out that a wet nurse may be more healthy and her vices may differ in quality from those of her mother, but on the other hand they may be less serious than those commonly found in wealthy women. He pooh-poohed the popular notion of a close harmony between the baby and his mother's milk, and the idea that an infant may thrive on a smaller quantity of it was, to his practical mind, absurd, though he believed that it was important for the stage of lactation in the nurse to correspond with the age of the suckling.

Brouzet concluded, somewhat tentatively, that cow's milk, goat's milk or van Helmont's formula are perhaps best of all, but he recalled that he himself sucked a drunken nurse for about 18 months with conspicuous success.

Finally he tackled the thorny problem of the advisability of prohibiting sexual intercourse during the period of lactation, treating the subject with typically French frankness. After some speculation he arrived at the conclusion that it is better for the nurse to enjoy the company of her husband than burn with the passions of unsatisfied desire, and by way of adding a personal recommendation he confided that he had not avoided lying with his wife and making love to her at these times yet their children had been well suckled. This moderate attitude has been paralleled in recent years over the question of smoking and drinking during the lactational period.

George Armstrong (? 1712-1764) opened the first dispensary for children in Red Lion Square, Holborn, where Walter Harris had died, and where William Cadogan, Jonas Hanway and James Nelson the apothecary lived. He wrote an 'Account of the Diseases Most Incident to Children' which was published in 1767 (revised edition 1783) based upon the experience he had gained whilst working amongst the children of the poor, to which was added an 'Essay on Nursing', a subject which was still commonly left to old women, nurses and midwives.

Armstrong was not particularly interested in breast feeding though he made the engaging comment that fond and anxious mothers sometimes make bad nurses, and he advised that a good wet nurse should have strong nerves lest the least surprise affect the milk, or sickness of the infant cause it to dry up when it is most needed. Hand feeding concerned him more presumably because of his work amongst the poor, and his own two children were reared in this way. 'There are two ways of feeding by hand; the one is by means of a horn, the other is with a boat or a spoon. They both have their advocates; but the latter, in my humble opinion is preferable' (p. 157). We shall include his graphic description of the horn in the section on the evolution of the feeding bottle in Part IV.

If the infant was to be hand fed from birth it should be given 'new cow's milk mixed with its victuals as often as possible, and now and then some of it alone to drink. Asses milk will be still better when available and the parents can afford it.' If the cow's milk was not 'new' it should be boiled and the pap, with which it was mixed, should be made from rolls rather than loaves since the latter were commonly bleached with alum. Hitherto most writers had regarded sugar merely as a flavouring agent, but Brouzet and Armstrong were among the first to appreciate the nutritive value of Lisbon sugar, though his recommendations in an earlier edition that it should be added to milk was not altogether well received (see his footnote to p. 161): 
'A very ignorant writer in the Political Register observes upon this passage, that there should be no sugar at all put into children's food; and the reason he gives for it, lest it should ferment in their stomachs. If this sage doctor was as skilled in his profession as one who sets up for a critic in it ought to be, he would certainly have known that digestion is partly a fermentatory process.'

At the age of 5 or 6 months the feeds should be thickened and broth, beef tea, minced chicken and bread pudding should be added gradually, with a rusk for the infant to chew as early as possible.

Armstrong described pyloric stenosis, but according to Still (1931) the first description emanated from Patrick Blair in 1717.

Hugh Smith (1730-90), Physician to the Middlesex Hospital, wrote several 'Letters to Married Women on the Nursing and Management of Children' which were published together in 1792 in a volume which might be described as the prototype of the modern mothercraft manual. In it, as might be expected, he strongly recommends breast feeding and indeed he apologizes for the necessity of having to raise such an obvious point at all. He believed that colostrum should be given to the newborn, that frequent suckling stimulated lactation, and that four hourly feeding at 7 a.m., 10 a.m., 1 p.m., 6 p.m. and 11 p.m. approximately is satisfactory after the first month. For hand feeding Smith advised the use of cow's milk (the 'properest substitute' for breast milk), which should be boiled if it purges, sweetened with Lisbon sugar if it constipates and be partially skimmed if it is a rich country product.

In Letter IX on page 124 he wrote in his amusingly intimate style:

\begin{abstract}
'What we have next to observe is the quantity of milk proper to a newborn child in 24 hours. What think you, my dear ladies, of a Winchester pint being a sufficient quantity for the day and night? Methinks I hear an exclamation-O barbarous man! Under a pretence of correcting us he intends to starve the little helpless creatures! Was there ever such a cruelty heard of before? Allow a child only a pint of milk a day! Why it would eat two quarts of pap and still cry for more-_. Yet after all surprise an infant in the month will receive from one pint of milk more real and good nourishment than from ten quarts of pap...
\end{abstract}

On a subsequent page Smith set down the actual quantities of undiluted cow's milk to be given to infants of various ages (calculation of a feed on the basis of the weight did not begin for another 100 years), and he was the first author to do so. During the first month 1 pint daily was to be given equally divided into four feeds, and this was gradually to be increased to 2 pints daily in five feeds by the age of 3 months, and thence up to 3 pints if the infant is still hungry but in whatever way you manage children, be careful not to feed them overmuch:

Hugh Smith is an important figure because we find in his writings the above views on the time and size of feeds, a description of his famous invention the 'bubby-pot' (to be included later), and the earliest signs of an awakening interest in, and awareness of, the constituent properties of milk, for he advised the addition of broth if the animal element was lacking and he pointed out that breast milk is deficient in cream and curd, whereas asses' and mare's milk approached nearest to human milk in constitution, yet cow's milk is cheapest and therefore best.

William Moss (? -1802), a Liverpool surgeon, is the last eighteenth century writer to merit individual attention since his 'Essay on the Management, Nursing and Diseases of Children', published in 1794, contains a large section on infant feeding which is full of good sense. Moss regarded breast milk as a perfect blend of animal and vegetable matter, or as a 'semi-digested intermediate state between the two', and he believed that the gastric juices of each animal were specially suited to the milk of that species. He was the first writer to challenge the traditional belief in the purgative action of colostrum, based upon his own observations made in the true scientific spirit that older babies, when put to the breast of a newly delivered woman to draw out her nipples, were not purged and that neonates, when fed with established milk from birth, did not require purgation in order to rid themselves of meconium. The use of colostrum was to him both natural and proper, especially since the common practice of giving pap and panada in the first week of life often lead to gripes, and even death, before the breast milk came in.

In appreciating, as Hugh Smith had done, the similarity between human and asses ${ }^{\circ}$ milk Moss was clearly influenced by the analyses of Thomas Young whose work first appeared in the form of a learned M.D. thesis entitled 'De Lacte' at Leyden in 1761 .

Moss believed that infant nursing was a subject of vital importance and for this reason his relationship with nurses and midwives was not a happy one for he deplored their habit of chewing the food first, and he deprecated the fact that many appeared to have complete dominion over the child, that they seldom submitted to medical advice and direction, that they were bound by prejudice and tradition and that they resented all interference as implied adverse criticism. Incidentally, one of the midwives duties was to sever the lingual frenum with her finger nail, an operation which was as frequently, and as 
unnecessarily, carried out as circumcision is today. He considered that one baby in every three or four had tongue-tie and that this was one of the commonest causes of breast feeding difficulties.

The latter half of the eighteenth century, as we have seen, witnessed a remarkable awakening of interest in the welfare of infants which, taken in conjunction with improved methods and deeper knowledge of infant feeding, was rapidly rewarded by a steady and profound fall in the appallingly high death rate of infants and children under the age of 5 .

At the close of the century four principal methods of infant feeding were extant:

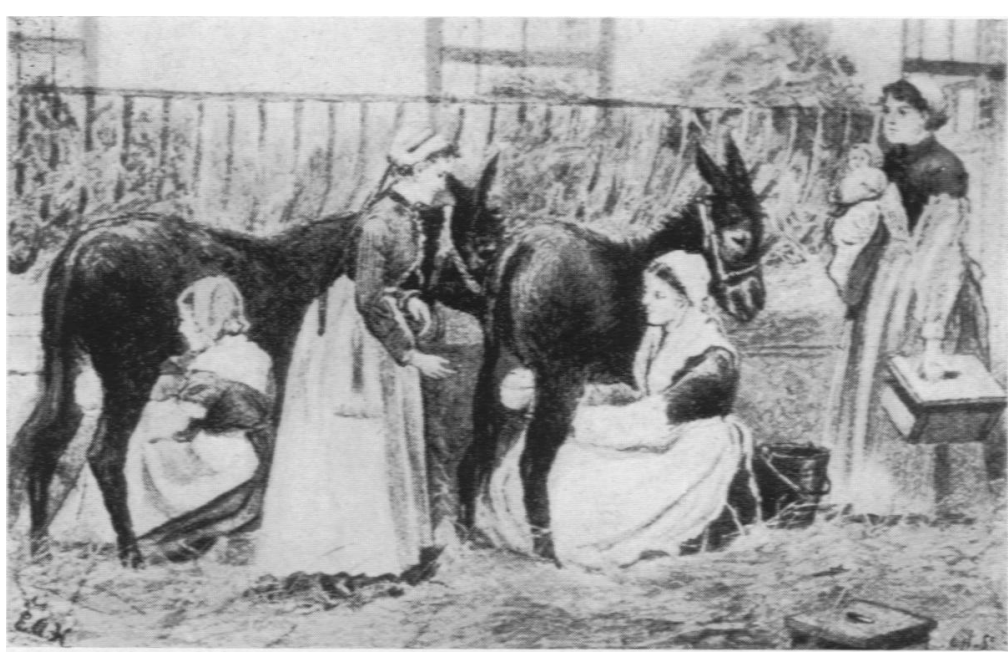

FK. 7.-Feeding infants directly with asses' milk at the Hospice des Enfants Malades. Reproduced from Sadler's 'Infant Feeding by Artificial Means' by kind permission of Messrs. Routledge and Kegan Paul.
(1) Breast Feeding by the Mother. This was usually practised with the early addition of pap. Only van Helmont and Brouzet were dubious of the supremacy of breast milk but their views were not widely held, even in France where an earlier writer, Jean Astruc (1746), had paid a fine tribute in a lecture in Paris to the far-reaching value of breast feeding:

'Nor should children be weaned until they are eighteen months or two years old, for the longer they suck the better, as good breast milk not only prevents many ailments, softens and cools the gums when inflamed, forwards dentition, and prevents its fatal consequences, but even lays a lasting foundation for a robust and healthy constitution and would prevent our having a diminutive generation of which our age is too productive.'

(2) Breast Feeding by Wet Nurses. The limitations of these women who were mainly destitute of all reason, knowledge and principle: in short of almost everything except mercenary prospects ${ }^{\circ}$ did not prevent William Buchan (1779) from recognizing the value of breast milk from whatever source it came:

Nature not only points out the food proper for infants, but actually prepares it. This however is not sufficient to prevent some who think themselves wiser than nature from trying to bring up their children without her provision. The mother's milk, or that of a healthy nurse, is unquestionably the best food for an infant. Neither art nor nature can provide a proper substitute for it.'

The transmission of character and temperament by breast milk was widely believed in, but for some reason the intellect of the growing infant was not liable to be affected in the same way; hence the increasing popularity of asses" milk

(3) The Use of Animal Milks. The latter half of the century saw an increasing interest in the use of animal milks in infant feeding though they had of course been widely used before, mainly by the peasant class. In Paris J. C. Desessartz (1760) recommended human, ass, goat, cow or ewe's milk in that order of preference based upon the size of the curd, and in the following year Young's thesis was published at Leyden. Alphonse Le Roy (quoted by Drake, 1930) was a great believer in the vital principle of milk, and in 1775 he instituted at Aix the direct suckling of foundlings by goats:

\begin{abstract}
'Each goat which comes to feed enters bleating [into the ward] and goes to hunt the infant which has been given to it, pushes back the covering with its horns and straddles the crib to give suck to the infant. There is in milk, beside the different nutritious principles, an invisible element, the element of life itself, a fugitive gas which is so volatile that it escapes as soon as the milk is in contact with the air. This is why it is impossible to rear infants with animal milk or with milk which has been expressed from the breast.
\end{abstract}

(4) Pap and Panada. Almost all the medical writers of the eighteenth century were appreciative of the danger of this mode of feeding, particularly when pushed to excess, but even as late as 1813 James Hamilton of Edinburgh (quoted by Drake, 1931) wrote that 'pap and panada be now almost universally used for the first food of infants, as a substitute for the mother's milk'.

In the nineteenth century we shall observe a 
decline in breast feeding as a result of the employment of women during the Industrial Revolution and a gradual falling off in the popularity of wet nurses except on the Continent, together with the supersession of various artificial foods as a substitute for breast milk, based upon primitive scientific principles. Pap and panada survived only amongst the most backward sects of the community, and the direct suckling from animals became prevalent only in France.

\section{Nineteenth Century Writers}

Michael Underwood's 'Treatise on Diseases of Children' in three volumes was first published in 1789. The fourth edition (1799) was the first to include, on the fly-leaf, a detailed chemical analysis of milk-a very important milestone along the road to the scientific approach to infant nutrition, the road which began with the famous nail test. The seventh edition (1819) bears the first real resemblance to a modern paediatric textbook and the third volume is entirely devoted to the management of infants including infant feeding.

The first fifty odd pages are filled with Underwood's views on Dr. Clarke's findings on the composition of human milk in Dublin in 1786, and the discourse which, beneath the veil of courtesy, has a distinctly acrimonious tone, is interesting to follow. According to Underwood, Clarke had asserted that: 'Woman's milk in a healthy state contains no coagulable or cheesy principle.' Underwood found by experiment that this was not so, but he noted that the curd took longer to form and was smaller which, he felt, reflected its added suitability for infants.

'If we find human milk out of the body so very slow in running into an acescent state, does it not afford strong presumptive evidence that the milk of nurses cannot be so very prone to run into acidity in the stomach of infants as authors endeavour to persuade us?' This assertion of Clarke's challenged the teaching of Walter Harris and was therefore repugnant to Underwood, though it must not be concluded that he completely accepted Harris' teaching, for on page 160 he relegated the role of acidity to a secondary place in the aetiology of infant disorders, 'the natural acid becoming morbidly acrid through overfeeding and other errors in the diet, and this acidity then aggravated the general condition. Underwood confirmed that breast milk was slow to turn sour in vitro though the rate varied with different samples; he kept specimens of human and cow's milk for long periods in phials on his mantelpiece, observing from time to time the development of the sour and putrid taste and smell. He concluded from these experiments that the souring process was fundamentally the same in both milks and that acidity was a cause of infantile dyspepsia, for did not breast fed pukings contain cheesy curds and turn litmus red?

Dr. Clarke had asserted that green stools were not a sign of acidity since in vitro most acids do not turn bile green. This argument carried no weight at all with Underwood for if some acids did then that was sufficient for him, and in any case infants who vomited frequently passed loose green stools which smelt sour and turned litmus red also.

With such crushing arguments at his disposal it is perhaps a little difficult to see why it was necessary to devote over fifty pages of the Introduction to them.

On the question of breast feeding, Underwood noted that it was becoming increasingly fashionable for ladies of rank to be maternally minded so that the evils of wet nurses and baby farming were declining and attention to difficulties at the breast was growing. In fact he seems to have been the first writer to have considered why it was that animals had so little trouble compared with man, and he concluded that the reason was that the latter had been 'designed to be the pupil of observation' with 'scarce any innate discernment'. In addition to these philosophical problems, he was also concerned with the mechanical barriers to successful lactation; thus on page 79 he recommended the use of Mrs. Relf's nipple shield for tender or retracted nipples which could be obtained from Mr. Savigny, surgeon's instrument maker, of Covent Garden. Underwood's interest in breast feeding, which might be likened to an oasis in the surrounding desert, has therefore many similarities to the work of Dr. Waller over 100 years later.

With regard to artificial feeding he closely followed the teaching of Hugh Smith whose bubby-pot met with his approval because the infant was made to work for his food rather than be overfed before he realized it; 'fed by means of it they are often hungry, and that is its highest recommendation.' Nevertheless he believed that in London only about one in eight survived hand feeding, and that those who thrived on spoon feeding would probably survive any regime, but art and good management may save many infant lives'.

Thomas Bull wrote the 'Maternal Management of Children' (3rd edition 1848) and 'Hints to Mothers' (1849), and set down the following rules for nursing for the guidance of mothers whose duty it was to breast feed their own children: (1) Put the newborn infant to the breast a few hours after delivery to draw out the nipples and stimulate secretion. The 
dosing of the newborn with castor oil or honey of roses and almond oil, though a common practice among midwives, was quite unnecessary. Of colostrum he wrote:

'It has been supposed by some that the milk first secreted is improper for the child-that it teases the bowels. The fact is, that it differs in an important respect from that which is secreted soon after; but then it is a difference which nature has ordained and designed for a wise purpose.'

Bull felt that primiparae would seldom be able to satisfy their offspring during the first four days of life, and for this period he advised offering halfstrength asses' milk or one-third strength sweetened cow's milk from a sucking bottle.

(2) The frequency of feeding must depend upon the infant's appetite during the first ten days.

(3) For the rest of the first month regular fourhourly feeds day and night were advised. Irregular feeding resulted in overloading of the stomach, dyspepsia, fever and often death.

(4) After the lying-in period an effort should be made to eliminate the night feed and so rest the mother. If possible, breast feeding without additions should continue until the teeth erupted; he deplored the still prevalent practice of giving panada, gruel or Naples biscuit during the first six months. Half-strength cow's milk was the substitute for the breast that he relied upon.

(5) Soon after the teeth appear, diluted cow's milk, farinaceous foods, broth, beef tea, etc. should be gradually introduced so that weaning was completed by the age of 12 or 18 months.

Bull mentioned that green stools, irritability and posseting were liable to occur in the breast fed baby when the mother was menstruating which necessitated temporary removal from the breast for young babies or complete weaning for older ones, as would a fresh pregnancy for infants of all ages. Wet nurses were considered to be preferable to hand feeding, and the usual characteristics are to be found indicating that even in the middle of the nineteenth century there was a lingering belief in the transmission of the passions in the milk. Before engagement the nurse should be asked whether menstruation had returned and in this respect there was no fear of concealment for it was commonly held that menstruation rejuvenated the milk though Bull recommended that if this was the case she should be rejected.

He was the first author to devote due consideration to the importance of psychological factors. He gave a very full account of a nervous mother's lack of experience in nursing and as this is the first detailed case history to be found in the literature it is worth recording in précis form.
A young mother gave birth to a healthy first baby whom she fed satisfactorily for three weeks. Then, in spite of an abundance of milk, the motions became lumpy, of mixed colour and dry, they were passed with great pain and frequent fits of crying occurred. The infant soon began to lose weight, the screaming fits became more frequent and violent especially after feeds until he fell back exhausted to sleep. 'It was very evident that the infant's hunger was not satisfied or its body nourished by the parent's milk, which, although abundant in quantity (the breast being large and full of milk), was at this time seriously deteriorated in quality. This was caused, I believe, from great anxiety of mind. Her monthly nurse became suddenly deranged and the whole responsibility and care of the child thus devolved upon the mother, while she was entirely ignorant of her duties. A wet nurse was obtained. In a very few hours after this change was effected, the screaming ceased, the child had quiet and refreshing sleep, and in twelve hours a healthy motion was passed.' He thereafter grew up into a fine healthy boy and the mother subsequently proved herself to be a good nurse to two later children.

It is entertaining to speculate upon the correct diagnosis here for we need not accept his conclusions without reservation, but we may certainly applaud his initiative in setting the facts before us. A more difficult problem to solve is to be found in von Ammon's remarkable story, which Bull repeats, of a nursing mother who separated her husband and another man who were fighting and then picked up and suckled her baby at once; he immediately died in her arms.

Charles West (1816-98), co-founder of the first children's hospital in the British Isles in Great Ormond Street in 1852, delivered a series of lectures on paediatrics to the students of Middlesex Hospital which were first published in 1848 . Lecture 27 in the first edition, and Lecture 31 in the revised seventh edition of 1884 , were solely concerned with infant feeding. It is of interest to compare and contrast the two lectures and thereby gain some insight into the progress made during the 36 years that intervened.

West put considerable emphasis on the chemical analyses of human and animal milks, quoting Professor Simon's 1838 figures in the first edition and Vernois and Becquerel's 1853 results in the later one. There was marked disagreement between the two sets of analyses but it can hardly be said that the French figures were notably more accurate than the earlier Berlin ones for both of them made the casein content of human milk extremely high, namely 3.1 and $3.9 \%$ respectively. Nevertheless they were sufficiently accurate for West to deduce that asses ${ }^{\prime}$ milk was a suitable substitute for breast milk and that cow's milk required diluting and sweetening to become 'humanised'. The micro- 
scopical examination of milk was coming into importance and the reaction was also studied. Breast milk and milk from cows at pasture were alkaline to litmus whereas a stall-fed cow produced milk which required diluting with lime water.

Even in the later edition there is a paragraph on the choice of a wet nurse who, in addition to the usually recommended features, should be a robust brunette. The partiality was presumably inspired by the work of L'Heritier who had analysed the milk of one blonde and one brunette and had found the latter's more nutritious. It was perhaps fortunate for blondes and redheads that wet nurses were dying out.

Two other points of interest appear for the first time in the revised edition. First, condensed milk gets its first mention though West was not very enthusiastic about it, pointing out that it contained less fat and albumen and more sugar than fresh milk so that it was less nutritious and more dyspeptic. Secondly, the test feed, though not described by that name, gets its first mention in an English textbook having first been described by $M$. Guillot in 1852 who, working at the foundling hospital in Paris, observed that infants under 1 month old, when weighed before and after feeds, recorded an increase of from 2 to 5 ounces, from which he calculated that they required about $1,000 \mathrm{~g}$. daily, i.e. 10 3-ounce feeds approximately. West was clearly markedly influenced by the work of contemporary Frenchmen, but he did not accept $M$. Tarnier's rejection of the feeding bottle on hygienic grounds, for he likened the alternative method of spoon feeding to the manner of fattening turkeys-there was no option but to take it or choke!

Pierre Budin (1846-1907), the famous French obstetrician and pupil of Tarnier, is the last important, but by no means the least important, nineteenth century writer on infant feeding. His published lectures were delivered in Paris at the end of the century though they were not translated into English by $W$. J. Maloney (under the title of 'The Nursling ) until 1907. As a result of Budin's work, French influence upon English paediatrics, which was prominent during the latter half of the nineteenth century, was carried over for several years into the twentieth.

Budin was a firm advocate of breast feeding and at the Maternité he maintained a permanent staff of wet nurses to suckle weaklings and other infants who would otherwise be deprived of breast milk. Furthermore he was proud to be able to state that $60 \%$ of the babies attending his clinic were wholly breast fed and $34 \%$ were partially breast fed, though these figures were not flattering since there must have been a strong tendency for the bottle-fed babies to continue to attend whereas the others would require less supervision.

If, however, breast milk was not available he prepared sterilized undiluted cow's milk which was distributed daily in sealed bottles each containing the appropriate quantity for one feed. This was notably unorthodox:

\begin{abstract}
'When I first advocated the feeding of infants on undiluted milk, critics asserted that infants could neither support nor digest it, and that it was responsible for quite a catalogue of evils-digestive troubles, rickets, eczema, urticaria, etc. I have never seen any bad trouble from its use.'
\end{abstract}

Cow's milk, because of natural variation and illegal dilution with water, was not of constant composition so he took care to ensure that the milk he distributed contained approximately $37 \cdot 35 \mathrm{~g}$. per litre of butter fat. His insistence on sterilization was inspired, as he freely acknowledged, by the work of Pasteur, and he did not subscribe to the common view that heat treatment destroyed certain vital principles in the milk, for he asserted that no case of rickets or scurvy developed under his care and he believed that these diseases were caused by over-dilution.

At his consultation de nourissons, the first of its kind in the world, accurate weight charts of each attending baby were kept, very similar to those in common use today. He accepted Bouchaud's figures for the average weight gain for a normal infant, namely $1 \mathrm{oz}$. daily for the first two months of life, $\frac{5}{6} \mathrm{oz}$. for the second two months and $\frac{2}{3} \mathrm{oz}$. for the third two months. He seems to have arrived at the correct food requirements by a process of trial and error; his formula was calculated by multiplying the infant's weight in grammes by two, and discarding the last digit. This gives a daily intake equivalent to $\frac{1}{5}$ body weight (the modern estimate of $2 \frac{1}{2} \mathrm{oz}$. per $\mathrm{lb}$. is rather less than $\frac{1}{6}$ body weight), and he appreciated that infants weighing less than $2 \cdot 8 \mathrm{~kg}$. required proportionately more. In common with all the previous writers, he described overfeeding as the 'scourge of infancy' and stated that 'it was better at first to give too little than too much' for an underfed infant failed to gain weight but it was free from digestive troubles. He mentioned one infant who showed a normal weight curve on an intake of only $\frac{1}{10}$ the body weight daily and curiously enough this has been taken to be his standard recommendation (see Powers, 1935, 'Budin's Rule'). Budin repeatedly reiterated his views on the danger of overfeeding.

In summary it may fairly be stated that Budin clearly and intelligently laid the firm foundations for 
the modern practice of infant feeding based upon breast feeding wherever possible or the use of sterile milk in quantities calculated according to weight rather than age which had hitherto been customary. His repeated insistence on the danger of overfeeding is readily understandable against the sombre background of epidemic cholera infantum prevailing at the time, but it was unfortunate that his followers saw fit to exaggerate his teaching and thus condemn a large number of French babies to a regime of chronic underfeeding.

Other Nineteenth Century Works. It would be tedious and unnecessarily repetitive to describe in detail the writings of all the nineteenth century paediatricians, but a few brief comments on the remainder will now be made.

C. A. Struve was a German physician whose work 'A Familiar Treatise on the Physical Education of Children' was translated into English by Willich in 1800. As Still (1931) has commented, it is difficult to see how the contemporary English could have derived benefit from this work which was definitely less advanced than those of Hugh Smith, Moss and Underwood.

C. H. F. Routh wrote an interesting book entitled 'Infant Feeding and Its Influence on Life' second edition 1863 , in which he showed that he was fully aware of the effect of diet upon infant morbidity and mortality, and he was one of the earliest writers to marshal statistics to prove his point.

Eustace Smith produced a work on 'The Wasting Disease of Infants and Children' which contained a large section on infant feeding in which he advised the practitioner to give 'plain, minute and exhaustive 'instructions on the recommended diet for an infant: his own directions admirably followed the pattern he had set.
Other late nineteenth century writers included Angel Money (1887), Mrs. Sadler (1896), who compiled facts and fancies from the works of contemporary experts, A. A. Beale (1894), whose comprehensive booklet on infant feeding and management cost only one shilling, and the appropriately named Pye Chavasse (1852) whose 'Counsel to a Mother' is both pompous and pontifical. Many paediatric textbooks were being born at this time such as those of J. F. Goodhart of Guy's, Ashby and Wright of Manchester and Emmett Holt of America, and all of them contained one or more chapters on infant feeding which summarized the current views of the day.

W. B. Cheadle's lectures on artificial feeding, six in all, were delivered at St. Mary's Hospital, London, and also at Great Ormond Street in 1887 (published in 1892) and are full of interest, especially with regard to his original views upon fat deficiency and rickets, lack of fresh foods and scurvy, and the use of raw meat juice and bread jelly.

Finally, Edmund Cautley (1897) produced by far the most complete and comprehensive textbook on infant feeding for the use of students and practitioners. It was over $\mathbf{4 0 0}$ pages long, comprising sections on the physiology of lactation, the management of breast feeding, the character and composition of breast milk with the factors liable to cause alterations in it, contraindications to breast feeding, weaning, comparison of cow's milk and breast milk, artificial feeding and the modification of cow's milk, proprietary infant foods, Dr. Vaughan's 'tyrotoxican' and micro-organisms in milk with its heat treatment, the feeding of prematures and the growth of normal infants. In fact this is the prototype of the modern textbook on infant feeding. 